\title{
A aula e a sala de aula: um espaço-tempo de produção de conhecimento
}

\section{The class and the classroom: a space-time of knowledge production}

\author{
Victoria Maria Brant Ribeiro'; Adriana Maria Brant Ribeiro²
}

R E S U M O

\begin{abstract}
Considera-se que a relação estabelecida entre professor e aluno é cultural, mas é também pedagógica, porque o espaço de convívio é mediado por conhecimentos que são, intencionalmente, ensinados e aprendidos. Nesse quadro, compreende-se que o exercício da docência deve, necessariamente, incluir momentos nos quais sejam feitas reflexão e crítica sobre as formas e o significado de ensinar, de trazer o outro para a sua perspectiva e com ele também aprender, momentos de experimentar situações desse acontecimento "feiticeiro" que se chama "sala de aula". São apresentados métodos e técnicas que possibilitam transformar estes momentos em oportunidades para construir conhecimento.
\end{abstract}

Descritores: Ensino. Aprendizagem. Métodos. Educação.

A aula e a sala de aula: um espaçotempo de produção de conhecimento

A sala de aula é de morte por abrigar vidas e, se distintas, ambas correm perigo. Pedro Geraldo Novelli (1997)

\section{APRESENTAÇÃO}

Q ueremos iniciar com uma pergunta que vem a ser título de livro bem conhecido: "Sala de aula: que espaço é esse?", organizado por Regis de Morais". E continuar com uma das possíveis respostas, fruto de nossa experiência de alguns anos: ela é um espaço de produção de conhecimento.

Tradicionalmente, a sala de aula é descrita e representada por um espaço físico onde convivem professores e alunos, sob normas estabelecidas e, em geral, vinculado à instituição escola. Ao mesmo tempo, a escola, como uma instituição, é o espaço no qual se transmitem valores e tudo o mais que a sociedade entende que deva ser (re)produzido pelas novas gerações. Nela cumprem-se rituais e as relações humanas que acontecem são de um tipo especial, na medida em que implicam um diálogo de culturas, em tempos e ambientes diferenciados. Trata-se de um encontro entre humanos e, talvez, precisamente devido a isso tenham desencontros ${ }^{2}$.
Nesse sentido, a relação que se estabelece entre professor e aluno é sempre uma relação cultural, mas é também pedagógica, porque o espaço de convívio é mediado por conhecimentos que são, intencionalmente, ensinados e aprendidos, desconstruídos, construídos ou reconstruídos em atividades que colocam esses sujeitos frente a frente produzindo teorias, discutindo conceitos e experiências, criando novos fatos, enfim, interagindo com suas subjetividades, por meio de conhecimentos compartilhados. Trata-se, portanto, de relação que pode, em alguns momentos, prescindir de um espaço físico, embora continue exigindo atenção constante para esse encontro de diferenças.

Nesse quadro, compreendemos que o exercício da docência deve, por um lado, necessariamente incluir momentos nos quais sejam feitas reflexão e crítica sobre as formas e o significado de ensinar, de trazer o outro para a sua perspectiva e com ele também aprender, momentos de experimentar situações desse acontecimento "feiticeiro" que se chama "sala de aula"; por outro, deve possibilitar a compreensão da complexidade do processo de formação e de seus determinantes, que transcendem, e muito, o espaço da própria escola e espera-se que construam possibilidades para sua transformação.

Este texto tem o propósito de permitir a reflexão sobre esses dois lados, considerando a especificidade da educação no campo da saúde.

1. Professora Associada - UFRJ/NUTE; Doutora em Educação pela UFRJ; 2. Assessora Técnica da Secretaria de Estado de Saúde - RJ; Cirurgiãodentista e Doutora em Educação pela UFF. 
der

Métodos e técnicas de ensinar e apren-

Antes de abordar este "encontro de diferenças", cabe situar o espaço sobre o qual estamos tratando: o processo de formação de profissionais de saúde que, necessariamente, é atravessado pelos conceitos de currículo, competência, método, técnica, integração e problematização.

Partindo do geral para o específico, defendemos a ruptura do conceito de currículo como uma lista de disciplinas que compõem um curso. No campo da formação profissional, currículo deve ser compreendido como um conjunto de ações que alunos, professores e comunidade realizam, por meio da comunicação verdadeira, correta e sincera, trocando conhecimentos e experiências para resolver problemas comuns: conhecimentos das ciências que conformam o campo específico da formação profissional; experiências das situações concretas de trabalho; problemas comuns que surgem na inserção conjunta (alunos e professores) em situações cotidianas da prática profissional.

Competência - termo de muitas interpretações, discordâncias e diferentes significados - define-se neste texto pela capacidade de os indivíduos mobilizarem suas potencialidades de forma integral, em contextos diversos; supõe o desenvolvimento de um conjunto de atributos que os habilitem a reconverter sua qualificação em outra (dependendo do que exijam novas funções), a conviver em grupo, sensível às diferenças, avaliar e atuar em novas situações enfrentando-as com criatividade ${ }^{3}$.

Método e técnica devem ser tratados em conjunto, na medida em que o primeiro, de maior abrangência, significa, segundo Mora ${ }^{4}$, uma ordem que se manifesta em um conjunto de regras, um certo caminho que seguimos para alcançar determinado fim; e a técnica é o procedimento que escolhemos para seguir com mais eficiência e eficácia este caminho. É disso que vamos tratar a seguir, pretendendo que o exposto contribua para transformar este encontro de diferenças em um espaço de produção conjunta (ou coletiva) de conhecimento.

\section{A problematização}

Iniciamos com o método que na experiência no campo da formação em saúde vem se mostrando cada vez mais eficiente e eficaz: a problematização, ressaltando que problematizar, na nossa compreensão, significa tornar algo complexo, problemático, duvidoso.

Se transferirmos este significado para o campo do ensino, podemos compreender por que a problematização é um método, mais que uma técnica, porque supõe uma concepção de educação, um modo de compreender o que seja o ato educativo. Portanto, reflete o modo de ser do professor, a forma como organiza seu plano de ensino, a seleção que faz dos conteúdos, das técnicas e da bibliografia, a maneira como conduz os encontros com os alunos (ou a aula, se preferir). Podemos, então, considerar que um professor com esta concepção dificilmente apresentará "facilidades" para os alunos; ao contrário, seu comportamento em relação aos alunos, aos conteúdos, às "verdades" teóricas, aos textos que seleciona etc. é sempre de dúvida, de provisoriedade. Quanto aos alunos deste professor, serão sempre "desconfiados", curiosos, mobilizados frente à enorme quantidade de conhecimentos que se produzem a cada minuto, inseguros porque aprendem que a verdade ainda está para ser encontrada.

Defendemos que, para o tipo de organização social de tempos atrás, eram aceitáveis a relação pedagógica e a prática docente baseadas na transmissão de conhecimentos. Os dias atuais, que apresentam sucessivos e intensos novos problemas, avanços tecnológicos, científicos e culturais imensuráveis, o que se transmite amanhã poderá estar em desuso em pouco tempo depois. Parece, pois, claro que o método da problematização ajusta-se a esse estado de dúvidas, de incertezas, e desenvolve as competências necessárias para que os alunos se tornem capazes de enfrentar desafios sempre novos, com habilidade suficientemente desenvolvida para buscar (ou encaminhar) as melhores soluções. O cenário e a fonte da problematização encontram-se na realidade concreta que, submetida ao método, com certeza se tornará realidade pensada, refletida.

\section{- ABP ou PBL \\ A Aprendizagem Baseada em Problema}

Decorrente do método da problematização, temos hoje muito em uso a técnica de Aprendizagem Baseada em Problema (ABP), por alguns conhecida por PBL (Problem Based Learning). Discutida, criticada, controvertida, aceita, adotada, muitos destes adjetivos são próprios dessa técnica que, por exemplo, não admite aula expositiva. Ora, em um modelo de ensino que resiste às inovações, em que professores com excessiva carga horária de trabalho e turmas numerosas encontram na aula expositiva (muitas vezes pronta há algum tempo) uma espécie de "porto-seguro", torna-se quase uma utopia transformar este modelo em outro que tem como centro o aluno, como estratégia um (ou mais) problema discutido, estudado, analisado e relatado em grupo, de preferência tutorial, e como avaliação instrumentos que diferem da conhecida prova.

Desenvolvida inicialmente na Universidade de McMaster, no Canadá, hoje é usada em várias instituições de ensino, sobretudo na área da saúde. São conhecidas as experiências de Maastrich, na Holanda, de Harvard e Cornell, nos EUA e, no Brasil, a Faculdade de Medicina de Marília, a Estadual de Londrina e a de Bragança Paulista vêm adotando a técnica com sucesso, segundo apresentações recentes em Congressos sobre ensino na área da saúde. Experiências pontuais também obtiveram e vêm obtendo sucesso. Entre elas, conhecemos a que foi desenvolvida em uma disciplina (Hematologia) na Faculdade de Medicina da UFRJ e outra em desenvolvimento na forma- 
ção pedagógica de mestrandos de Medicina e de Odontologia da mesma Universidade.

Cyrino e Toralles-Pereira ${ }^{5}$ afirmam que a problematização e a aprendizagem baseada em problema se apóiam na aprendizagem por descoberta e significativa, as quais valorizam o aprender a aprender.

A atividade tem peculiaridades especiais: o ensino é centrado no aluno, a aprendizagem se dá sob a forma de busca ativa, construção de pequenos textos sobre o problema para que sejam devidamente discutidos no grupo. Os grupos devem ser de dez a quinze alunos no máximo e contam com um professor-tutor, cuja função é dinamizar as atividades do grupo, sem intervir com explicações ou aulas expositivas sobre dúvidas comuns.

A técnica é conhecida pelos "sete passos", sendo o primeiro a leitura do problema construído pelo professor ou, idealmente, pelo grupo de professores da mesma disciplina ou de disciplinas afins. Trata-se de um problema a ser estudado e não necessariamente a ser solucionado e pode ou não ser construído com base em situações reais.

Os "sete passos", coletivamente seguidos, são: 1) ler atentamente o problema (professor e alunos) e esclarecer todas as dúvidas ou termos desconhecidos; 2 ) identificar as questões, os conceitos ou os temas importantes abordados no problema ("chuva de idéias"); 3) discutir as "ideias" levantadas, articulando-as com conhecimentos prévios do grupo; 4) sistematizar as principais "ideias" em conjuntos categorizados que norteiam o trabalho do grupo; 5) construir os objetivos (ou questões) de aprendizagem que levam ao aprofundamento das "ideias" em questão; 6) estudo e registros individuais sobre os temas do problema para discussão em grupo; 7) rediscussão do problema no grupo tutorial, apresentando o material consultado, estudado e registrado, de modo a integrá-lo no relatório final do grupo.

O relatório é a culminância da técnica e deve refletir o empenho de todos os componentes do grupo. $\mathrm{E}$ neste aspecto reside a maior relevância da técnica, pois a integração de consultas e estudos variados sobre o mesmo problema torna a aprendizagem mais duradoura.

Do ponto de vista do aluno, a experiência que conhecemos parece transcender, em muito, o lugar do esperado método de transmissão do conteúdo programático e assume o lugar de uma forma autônoma de conduzir o trabalho a ser realizado no interior de uma disciplina. Uma ousadia, certamente, segundo os alunos. O curso foi virado "de ponta-cabeça", segundo avaliação de outros. Há um conteúdo programático a ser trabalhado, e que é comunicado, mas aos alunos é conferido o lugar de construtores desse conhecimento, depoimento ainda de alunos submetidos à técnica. Desnecessário afirmar que a proposta suscitou nos alunos, inicialmente, uma certa dose de desconfiança que, de alguma forma, se fez acompanhar de insegurança do docente, agora estreando na função de tutor, novidade para ambos os lados. Retirados dos lugares comuns, de costume, o que se propõe realizar não oferece espaço para transmissão de saberes: todos aprendem juntos e, no início, sem muita clareza na definição dos papéis. Trata-se de uma proposta que obviamente caminha na contramão de tudo o que se vive nas trajetórias acadêmicas de todos os envolvidos. Mas no final do curso, em momento de avaliação que não deve deixar de ser realizado, o grupo reconhece que todos os objetivos propostos no início do curso foram alcançados e que a aventura da opção por trabalhar com o método ABP resulta em uma aprendizagem bastante significativa. E significativa também é a observação de um aluno ao avaliar o método: Comecei a acreditar na ABP quando, após horas de discussão e pesquisa em grupo, conseguimos estudar grande parte do conteúdo programático em um único problema.

A esse depoimento é possível acrescentar que o fato de o grupo se auto-gestionar, traz benefícios da ordem da autonomia, do compromisso com o resultado da equipe, e, mais do que tudo, do exercício da busca ativa do conhecimento, uma conquista que só enriquece a concepção de ensino indissociável da pesquisa.

As críticas dizem respeito, fundamentalmente, à impossibilidade de adotar o método em turmas com cerca de cem alunos, argumento absolutamente válido, mas não impeditivo. É possível recorrer a monitores, alunos de níveis mais avançados, desde que sejam preparados para a função de tutor. Outro argumento refere-se à dificuldade na montagem do problema de modo que dê conta dos conteúdos e objetivos do programa. De fato, essa não é uma questão trivial, mas a prática docente conta com três grandes aliados: a criatividade, a autonomia e o contato sistemático com novas gerações. Sozinhos, sem dúvida, esses aliados podem se transformar em adversários, o que significa dizer que requerem a necessidade imperiosa de transgredir, de estar disposto a romper modelos cristalizados e ser capaz de suportar críticas pela ousadia, de continuar (sem olhar para trás!) no caminho que leve à transformação social com os instrumentos, as ferramentas e os sujeitos pelos quais somos responsáveis.

\section{A aula expositiva}

Outra técnica a ser aqui tratada - e que se situa em oposição à $A B P$ - é a mais conhecida e a mais usada na atividade docente desde o tempo da educação jesuítica, que dela se valia para a catequese dos índios. Alguns a chamam de "aula teórica".

Mudaram os tempos, mudaram as pessoas, mudaram os interesses. Hoje, não há mais lugar para a aula expositiva que "catequisa" porque não há mais espectadores passivos, submissos, razão pela qual esta técnica deve ser dialogal. Escolhe-se um tema do programa, que comporte uma exposição oral dialogada, prepara-se um roteiro dos tópicos mais importantes, faz-se uma busca bibliográfica atualizada sobre o assunto, ampliam-se as conexões do assunto com outras áreas do conhecimento, formula-se uma série de questões (que não são perguntas) que levantam suspeitas sobre o que se está explanan- 
do, fazem-se interrupções estratégicas de modo que os estudantes reflitam sobre as questões e tenham possibilidade de contestar ou solicitar esclarecimentos e, por fim, constrói-se com os alunos uma síntese dos principais pontos abordados.

\section{O seminário}

Outra técnica quase tão usada quanto a aula expositiva é o seminário, considerado por muitos mais democrática e mais participativa porque "obriga" os alunos a estudarem um mesmo tema, o qual usualmente é apresentado por um deles, contrariando o significado original da técnica.

Uma das mais fiéis descrições de seminário pode ser encontrada em um livro de Metodologia Científica ${ }^{6}$, e nos oferece condições de desconstruir esta imagem meio desgastada da técnica: Um dos sentidos da palavra seminário mais próximo da sua origem etimológica é: um viveiro de plantas onde se fazem sementeiras. Segundo a autora, este significado mostra toda a força contida nesta técnica, contrariando a monotonia que, em geral, a caracteriza. Seu papel é, ainda segundo a autora, de lançar sementes, novas idéias, novas perspectivas de pesquisa para os participantes. Trata-se, portanto, de um momento importante de discussão, de debate, de problematização e de síntese de muitas idéias sobre o tema, o que significa que deve haver uma preparação conjunta, planejada criteriosamente pelo professor e pelos alunos responsáveis pela atividade.

Os dois primeiros passos do seminário são fundamentais para se garantir sua finalidade: a escoIha do tema e a definição do objetivo. Realizados esses passos, é chegado o momento da consulta bibliográfica e da seleção de um texto que deverá ser distribuído com antecedência para toda a turma. Os responsáveis pela condução da técnica, que se aprofundam no estudo do tema, elaboram um roteiro para o momento da atividade, e é recomendável que solicitem à turma que prepare questões sobre o textobase de leitura comum.

Para que se torne um "viveiro de plantas", a realização da técnica inicia-se com uma breve explanação do objetivo, e uma síntese dos principais pontos que devem ser discutidos em grupo. Os grupos, que conhecem o assunto pela leitura do texto-base, preparam, por sua vez, e sob a supervisão da equipe responsável, síntese das questões levantadas, as quais são levadas à plenária para discussão coletiva, oportunidade na qual professor e responsáveis agregam conhecimentos da bibliografia consultada anteriormente. O momento é dinâmico, polêmico, problematizador, razão pela qual se deve indicar um relator que anota questões recorrentes, dissensos, outros conhecimentos relacionados ao tema para, ao final, fornecer elementos que possibilitem construir, também coletivamente, uma nova síntese, ampliada, sistematizada, indicadora de novas buscas.
Como se pode observar, o seminário ao qual estamos acostumados tem outra dinâmica e, muitas vezes, assume o caráter de transferência da aula que deveria ser de responsabilidade do professor para o aluno, ou para um grupo de alunos. Construir um "viveiro de plantas" em sala de aula envolve um número muito maior de jardineiros.

\section{Painel}

Esta técnica exige uma preparação semelhante à do seminário. Usa-se para introduzir um tema ou para problematizar um assunto que merece aprofundamento e tem como protagonistas também um grupo de alunos orientados pelo professor.

Tal como no seminário, escolhe-se o tema e o grupo responsável (os painelistas) se prepara consultando bibliografia com enfoques diferenciados, de modo que componha uma espécie de mesa de discussão, tendo a turma como platéia.

Cabe lembrar que a turma, tal como no seminário, deverá ter conhecimento do assunto antecipadamente, por indicação bibliográfica do grupo de painelistas. 0 fato de haver uma discussão de posições diferenciadas sobre o mesmo assunto desperta o interesse de todos e substitui, com vantagem, a exposição oral de uma só pessoa. Anastasiou e Alves ${ }^{7}$ atribuem ao painel o desenvolvimento de diversas operações mentais: obtenção e organização de dados; observação; interpretação; busca de suposições; crítica; análise. A estas operações podemos acrescentar a capacidade argumentativa, na medida em que os diferentes enfoques polemizam o tema e exigem dos painelistas argumentos de defesa de suas posições. Interessante é que se provoque a turma para aderir a essas diferenças, abrindo-se espaço, ao final do debate, para manifestação da platéia. E esse pode ser um momento oportuno para que o professor ressalte os pontos importantes, sistematize o tema, avalie a competência argumentativa dos manifestantes e até aproveite para apontar interfaces com outros conhecimentos, ou estimule que os alunos o façam.

Quanto aos painelistas, entre eles, há de se desenvolver uma habilidade um tanto desprezada, porque difícil de sustentar: a dissonância cognitiva, ou seja, defender algo que muitas vezes somos contra (e o contrário também).

\section{A aula demonstração}

Especialmente no campo da saúde, a aula demonstração assume importante papel, na medida em que possibilita traduzir em uma prática determinados conceitos teóricos, apresentar provas concretas e reais de teorias, criar oportunidade de desenvolver habilidades necessárias para o cuidar. É uma das possibilidades que tanto anunciamos de presenciar a integração da teoria com a prática, razão pela qual deve ter planejamento especial em que objetivos, conteúdos, materiais, métodos e, principalmente, medidas de segurança sejam previstos, selecionados e 
providenciados. Veiga ${ }^{8}$ descreve e apresenta objetivamente não só a técnica como suas finalidades.

Basicamente, a demonstração visa a mostrar como se faz uma tarefa, uma operação, envolvendo ação com materiais diversos - ferramentas, equipamentos e máquinas - demonstrar conceitos, teoremas, comprovar afirmações etc. É uma técnica de ensino que leva em conta os interesses dos alunos, os ritmos de aprendizagem.(...) A demonstração permite que o professor perceba o aluno como sujeito de seu processo de aprender, uma vez que ele coloca ênfase na atividade do estudante, sua participação, sua iniciativa e responsabilidade na execução de um determinado projeto de trabalho, tarefa ou operação, e na proposição de soluções.

Modernamente, recursos tecnológicos virtuais permitem apresentar demonstrações que independem da presença dos instrumentos; são, sem dúvida, complementos importantes, mas a realidade do trabalho em saúde exige competências e habilidades específicas que tornam a demonstração presencial insubstituível.

Quanto às habilidades específicas não há dúvida em relação às motoras; entretanto, a aula demonstração abre ume leque muito mais abrangente de competências: a integração de conhecimentos teóricos e práticos (como já vimos), a interação dos participantes (professores e alunos), a problematização de conteúdos (sobretudo provocada pelo professor), o exercício da técnica (indispensável em procedimentos curativos de modo geral) e, sobretudo, a possibilidade de duvidar e comprovar. Veiga ${ }^{8}$ aponta as vantagens desta técnica.

O fato de o professor empregar a indagação e o questionamento como formas de conduzir a aula provoca nos alunos uma disponibilidade maior de participar com suas próprias questões e dúvidas a fim de atingir os objetivos propostos. O aluno precisa ter chances para expor suas idéias, falando ou escrevendo, levantar questões, elaborar e testar hipóteses, discordar, argumentar, propor soluções, corrigir e avaliar a sua aprendizagem. Em síntese, o aluno deve ser estimulado e encorajado a refletir, experimentar, manipular aparelhos e equipamentos a fim de explorar e inovar, sem medo do fracasso e da crítica.

\section{show e outros)}

Aula com uso de imagem (vídeo, filmes, data-

Considerando que vivemos hoje em plena era da informação e da comunicação, na qual a imagem ocupa lugar de destaque, cabe refletir sobre este recurso, o uso que dele se faz e o potencial que traz para o processo educativo.

É por todos conhecido o apelo da mídia por meio da imagem. Cada vez mais sofisticados, os anúncios vendem, os filmes "computadorizados" têm bilheteria garantida, a ambientação de novelas usa a mais alta tecnologia em efeitos criativos. Enquanto isso acontece em um simples clicar de botão, a escola, com raras exceções, tenta acompanhar este movimento, mas com desvantagem quase insuperável: falta de recurso, vídeos e filmes desatualizados, transparências em retroprojetor (muitas delas feitas pelo próprio professor), e o agora muito usado data-show. Sem dúvida, as finalidades são diferentes, mas o forte apelo de fora reduz o interesse por recursos que, para o professor, representam uma espécie de suporte-garantia de aulas mais modernas, que mesclam imagens à sua exposição oral; para o aluno, segundo relatos recorrentes, representam (também com raras exceções) a substituição do professor por um conjunto de figuras-ações-representações gráficas muito aquém do que se oferece nos meios de comunicação.

Há equívocos a serem retificados com urgência. A aula com imagem deve ser problematizadora e não somente informativa. O que se elege como recurso visual, de preferência atualizado, deve ser de curta duração (no máximo quinze minutos) e precedido de breve exposição oral sobre o objetivo da atividade. Após a exibição do recurso, cabe ao professor conduzir o debate sobre a problemática apresentada, para o quê se prepara com uma questãoproblema dirigida à turma e um roteiro particular dos pontos a serem ressaltados, caso a discussão siga rumos não previstos; neste caso, também deve o professor buscar nestes rumos o que há de comum ou de aproximações com o objetivo definido inicialmente.

É importante ressaltar que a imagem é sempre útil como recurso complementar ou suplementar; nunca como recurso substitutivo das discussões em grupo, da busca em bibliotecas, ou da exposição dialogada do professor.

\section{Grupo focal}

Utilizado com mais freqüência em trabalhos de pesquisa, o grupo focal é uma técnica promissora também para o ensino, desde que tenhamos clareza da importância cada vez maior da indissociabilidade destas duas funções da universidade. O único problema em turmas com grande número de alunos, mas que pode ser estratégico para trabalhos em grupo, é o fato de só poder se realizar com no máximo quinze pessoas reunidas, para aprofundar ou avaliar conceitos, identificar problemas. Substitui, por exemplo e com vantagem, as entrevistas, pois a palavra é livre de coação e o debate com outros participantes enriquece o tema em discussão. O debate é gravado, com consentimento livre e esclarecido dos participantes, as falas são transcritas integralmente, depois analisadas e classificadas por "núcleos de sentido"9 para compor um textorelatório que pode ser a solução de um problema, um programa, o aprofundamento de determinado assunto, enfim, o que importa é o desenvolvimento de competências tais como: usar argumentos consistentes na defesa de idéias, respeitar a palavra do outro e, especialmente, democratizar o debate em grupo.

Na verdade, trata-se de uma "situação ideal de fala"10 na medida em que estabelece conexões entre possíveis atividades ou problemas que se ofereçam em um currículo, objetivando a formação de competência 
argumentativa e da conseqüente tomada de consciência, por parte dos professores e alunos, de que correm o risco de terem sempre postos em questão os argumentos dos seus discursos. Sem dúvida, formar vontades e opiniões que sejam reciprocamente acordadas, por meio de situações ideais de fala, com base em ações orientadas ao entendimento, pode ser um meio de formar o sujeito autônomo e competente.

\section{Uma observação na conclusão}

É inadiável a inovação no modo de ensinar e de aprender. Aceitamos e adotamos todo tipo de tecnologia que o mercado nos oferece; algumas delas acabam por fazer parte da nossa própria natureza. No entanto, resistimos às tecnologias educacionais inovadoras e aí cabem muitas indagações, muito tempo de discussão e de reflexão sobre os motivos desta resistência. Técnicas e métodos de ensino que possibilitam inovar a prática pedagógica são inúmeros. Os aqui selecionados tiveram como critério serem os mais freqüentemente utilizados. A questão é ter clareza que nenhum deles, por si só, produz efeitos de transformação social. O que vale e faz a diferença é a vontade firme dos sujeitos das ações educativas - professores e alunos - de entrar no complexo processo de desconstrução e reconstrução, cada um de si e cada um de todos.

\title{
A B $S$ S T $R$ R A C $C$
}

\begin{abstract}
The teacher/student relationship is considered to be cultural, but it is also pedagogical, as it is established by means of the knowledge intentionally taught and learned. In this scene, the teaching activity must, necessarily, include moments of reflection and criticism, during which the meaning and the teaching methods must be brought about by presenting the student with one's own perspective, while at the same time learning from him, as well as moments in which both will experience and exchange this "magic" event called "classroom". This essay presents methods and techniques which make it possible to turn these moments into opportunities for knowledge building.
\end{abstract}

Key words: Teaching. Learning. Methods. Education.

\section{REFERÊNCIAS}

1. Morais R, organizador. Sala de aula. Que espaço é esse? Campinas: Papirus; 1986. 136p.

2. Novelli PG. A sala de aula como espaço de comunicação: reflexões em torno do tema. Interface/UNESP. 1997;1(1):43-50.

3. Brant-Ribeito VM. Discutindo o conceito de inovação curricular na formação dos profissionais de saúde: o longo caminho para as transformações no ensino médico. Trabalho, Educação e Saúde. 2005;3(1):91-121.

4. Mora JF. Dicionário de Filosofia. Buenos Aires:Sulamericana. 1971, Método; p.197-200.

5. Huhne $\mathrm{H}$, organizador. Metodologia Científica: caderno de textos e de técnicas. $4^{a}$ ed. Rio de Janeiro:Agir. 1990. 263p.

6. Anastasiou LGC, Alves LP. Processos de ensinagem na universidade: pressupostos para as estratégias de trabalho em aula. Joinville:UNIVILLE. 2003. 145p.

7. Veiga IP. Relatório de observação, dos professores/alunos matriculados na disciplina Didática de Educação Tecnológica. Curso de Especialização, convênio CEFET-RJ e SENETE-MEC. Brasília: Secretaria Nacional de Educação Tecnológica. Ministério da Educação, 1990. p.131-46.
8. Minayo MCS. O desafio do conhecimento. São Paulo: Hucitec. Rio de Janeiro: ABRASCO. 2000. 269p.

9. Habermas J. Teoría de la acción comunicativa: complementos y estudios previos. Madrid: Cátedra. 1994. 507p.

10. Bordenave JD. A pedagogia da problematização na formação dos profissionais de saúde. Folha de São Paulo. 2003 Set 27: Sinapse.

Recebido em 10/09/2010

Aceito para publicação em 30/10/2010

Conflito de interesse: nenhum

Fonte de financiamento: nenhuma

\section{Como citar este artigo:}

Ribeiro VMB, Ribeiro AMB. A aula e a sala de aula: um espaço-tempo de produção de conhecimento. Rev Col Bras Cir. [periódico na Internet] 2011; 38(1). Disponível em URL: http://www.scielo.br/rcbc

\section{Endereço para correspondência:}

Victoria Maria Brant Ribeiro

E-mail:victorianutes@gmail.com 